\title{
ANÁLISE INTEGRADA DA PAISAGEM: PERFIS GEOECOLÓGICOS NA TRANSIÇÃO PLANALTO OCIDENTAL - DEPRESSÃO PERIFÉRICA NO MUNICÍPIO DE SÃO PEDRO, ESTADO DE SÃO PAULO
}

Fernanda RAMOS

André Mateus BARREIROS

Fernando Nadal Junqueira VILLELA

Marcos Roberto PINHEIRO

\begin{abstract}
RESUMO
O presente artigo aborda as contribuições advindas do uso de perfis geoecológicos na análise integrada da paisagem. A pesquisa foi baseada no estudo de transectos na transição do Planalto Ocidental para a Depressão Periférica em São Pedro - SP, e buscou compreender a organização e dinâmica da paisagem local, de modo a hierarquizar as forças atuantes em uma perspectiva geossistêmica. Fazendo uso de bases cartográficas, fotografias aéreas e imagem SRTM, levantaram-se características geológicas, geomorfológicas, pedológicas e hidrográficas, bem como a vegetação original e uso da terra atual. Ainda no contexto geográfico, foi possível estabelecer relações sistêmicas entre os temas escolhidos e suas respectivas escalas de atuação, verificando-se a interação dos elementos que compõem a paisagem a partir de um perfil síntese, permitindo também melhor compreensão da atuação antrópica na área de estudo. Os resultados demonstraram forte influência de caráter litoestrutural, assim como uma ocupação antrópica dependente das condições topográficas e pedológicas.
\end{abstract}

Palavras-chave: Geomorfologia; Escarpa de Cuesta; Geossistema; Geoecologia; Perfil Geoecológico.

\section{ABSTRACT}

LANDSCAPE INTEGRATED ANALYSIS: GEOECOLOGICAL PROFILES IN THE TRANSITION BETWEEN THE WESTERN PLATEAU AND THE PERIPHERAL DEPRESSION IN SÃO PEDRO MUNICIPALITY, STATE OF SÃO PAULO, BRAZIL. This article focuses on the use of geoecological profiles as a contribution to landscape integrated analysis. The research was based on the study of transects in the transition between the Western Plateau and the Peripheral Depression in São Pedro Municipality, State of São Paulo - Brazil, and aimed to understand the organization and dynamics of the local landscape, in order to hierarchize the forces at work under a geosystemic perspective. Using cartographic bases, aerial photographs and SRTM images, geological, geomorphological, pedological and hydrographic characteristics were surveyed, as well as the original vegetation and current land use. Within a geographical context, it was possible to establish systemic relationships between the chosen themes and their respective scales of action, attesting the interaction of elements that compose the landscape by means of a synthesis profile, which also allowed for a better understanding of the anthropic interference in the study area. The results showed a strong influence of lithostructural character, as well as an anthropogenic occupation dependent on topographic and pedological conditions.

Keywords: Geomorphology; Cuesta Escarpment; Geosystem; Geoecology; Geoecological Profile. 


\section{INTRODUÇÃO}

No Estado de São Paulo a Bacia Sedimentar do Paraná é caracterizada pela presença do relevo assimétrico de cuestas na borda do Planalto Ocidental (ALMEIDA 1949, AB'SÁBER 1972, ROSS \& MOROZ 1997), sendo sua morfologia uma das mais expressivas da bacia. No conjunto do relevo de cuestas, há subdivisão em sistemas serranos sedimentares, no qual destaca-se a Serra de São Pedro, cuja configuração como forma de relevo cuestiforme ocorre na transição entre a Depressão Periférica e o Planalto, com o relevo caracterizado pela geometria suave no reverso, vertentes escarpadas na frente da Serra e um conjunto de colinas alongadas (glacis) defronte à escarpa. Esses elementos morfológicos são descritos como os componentes fundamentais do relevo de cuestas na literatura geomorfológica (GOUDIE 2014).

A partir da investigação da gênese dos materiais dos sopés das cuestas no mundo tropical, particularmente na região de São Pedro/SP, no sentido de determinar se aqueles eram autóctones ou alóctones, quais eram as suas relações com a evolução do relevo e como se configuravam as superfícies produzidas pelos processos atuantes no decorrer da história geológica, foram levantadas muitas dúvidas sobre a gênese e evolução da paisagem em foco, sobretudo quanto aos aspectos geomofológico-pedológicos (VILLELA et al. 2018). As questões apresentadas, bem como aquelas indicadas na literatura clássica da área (QUEIROZ \& JOURNAUX 1978; DIAS FERREIRA 1997; OLIVEIRA 1997; FURQUIM 2002; FURQUIM et al. 2013; PINHEIRO 2014; PINHEIRO \& QUEIROZ NETO 2015, 2017), demonstraram a complexidade do problema investigado, reforçando a ideia de que apenas uma investigação ampla, baseada no alicerce forma-material-processo, poderia efetivamente esclarecer os problemas relativos à gênese e evolução geomorfológico-pedológica no eixo Planalto Ocidental - Depressão Periférica.

Além de verificar a gênese do modelado de relevo e dos solos, também se lançou na investigação o contexto neotectônico da região, possibilitando melhor compreensão da relação entre modelado de relevo, processos e materiais na transição Planalto Ocidental - Depressão Periférica Paulista (PINHEIRO et al. 2019, CIANFARRA et al. 2019). Porém, dado o caráter complexo da área de estudo, exemplificado pelas transições do domínio da escarpa de cuesta para as colinas da Depressão
Periférica, não foram totalmente esclarecidos os aspectos e associações quanto à litoestrutura e características do modelado de relevo, tais como rupturas de declive e cobertura pedológica, muito pela falta da análise de transectos que compreendessem a espacialização e conexão destas unidades geomorfológicas em uma perspectiva integrada.

A partir disso, a elaboração de perfis geoecológicos, enfoque desta discussão, veio a contribuir na investigação e escopo das questões e estudos anteriormente citados. A concepção geoecológica permite verificar transições entre unidades geomorfológicas que contemplem não apenas o quadro geomorfológico e pedológico, mas também o contexto geográfico dos diferentes temas que podem ser abordados segundo objetivos pré-definidos de uma determinada pesquisa, tais como as associações entre litologia, modelado de relevo, solos, rede de drenagem e uso da terra, entre outros, configurando, em última instância, análise funcional da paisagem voltada ao seu aspecto fisiológico (AB’SÁBER 1969, CONTI 2011).

Nesse contexto, o objetivo deste trabalho é apresentar as contribuições advindas do uso de perfis geoecológicos no estudo integrado da paisagem, a partir da análise de transectos na transição do Planalto Ocidental para a Depressão Periférica em São Pedro - SP.

\section{MATERIAL E MÉTODOS}

\subsection{Fundamentação teórica}

Partindo-se da Teoria Geral de Sistemas (BERTALANFFY 1950) e da Geoecologia da Paisagem (TROLL 1971), a paisagem é considerada um sistema complexo sobre a superfície terrestre, numa combinação dinâmica de elementos físicos, biológicos e antrópicos, com diversas escalas de grandeza temporais e espaciais. Também pode-se resgatar o conceito de DELPOUX (1974), onde a paisagem é definida como uma entidade espacial correspondente à soma de um tipo geomorfológico e de cobertura num sentido mais amplo da palavra. Nessa visão, é possível assumir que a superfície terrestre compõe uma relação geossistêmica: trata-se de uma unidade espacial que apresenta uma dinâmica de interações, sendo estas entre processos naturais e sociais, estes últimos relacionados, entre outros, ao uso e ocupação da terra. Sendo assim, a paisagem da Serra de São Pedro pode ser analisada como uma integração geográfica regional, em per- 
pétua evolução, representando um conjunto único e complexo (MONTEIRO 2001).

Para AB'SÁBER (1969), a paisagem em geografia física é determinada pela análise integrada dela, isto é, levando em consideração a compartimentação (plano horizontal), a estrutura superficial (plano vertical) e a fisiologia da paisagem, sendo esta última descrita pela complexa gama dos processos dinamizadores da superfície terrestre, incluindo a sociedade.

No exercício de síntese para a compreensão da constituição, estrutura e dinâmica de uma paisagem em determinada área, a construção de perfis geoecológicos tem contribuído para melhor entendimento da paisagem por meio de transectos que, segundo temas escolhidos, demonstram as correlações geográficas. Essas interações são expressas nos perfis a partir de uma espacialização bidimensional dos fenômenos, que são baseadas nas relações topológicas, topográficas, altimétricas e estruturais, entre outras variáveis que podem ser elencadas para a análise dentro dos objetivos de uma dada pesquisa (BEROUTCHACHVILI \& RADVANYI 1978; MONTEIRO 2001; MANOSSO 2008, 2013; ROCHA et al. 2018).

\subsection{Procedimentos operacionais}

Para que fosse possível representar os transectos por meio de temas nos perfis geoecológicos e chegar-se a um perfil síntese representativo da paisagem, foi preciso a combinação de uma série de informações a partir de atividades de gabinete e levantamentos de campo. Inicialmente em gabinete, procedeu-se à escolha da localização e orientação dos transectos a partir de uma análise da Carta Geomorfológica de São Pedro e do Baixo Piracicaba (PINHEIRO \& QUEIROZ NETO 2016) (Figura 1), onde buscaram-se alinhamentos que representassem uma síntese da distribuição e interação dos distintos elementos naturais e sociais da transição Planalto Ocidental - Depressão Periférica. O traçado dos perfis foi executado preferencialmente sobre o topo dos interflúvios, a fim de se destacar os divisores topográficos, as cabeceiras de drenagem, os colos e fundos de vale, principalmente aqueles morfologicamente contrastantes com os divisores a partir de rupturas de declive no meio das vertentes, demonstrando maior gradiente entre os topos e fundos de vale. Todos os transectos tiveram orientação $\mathrm{N}-\mathrm{S}$, desde a transição do

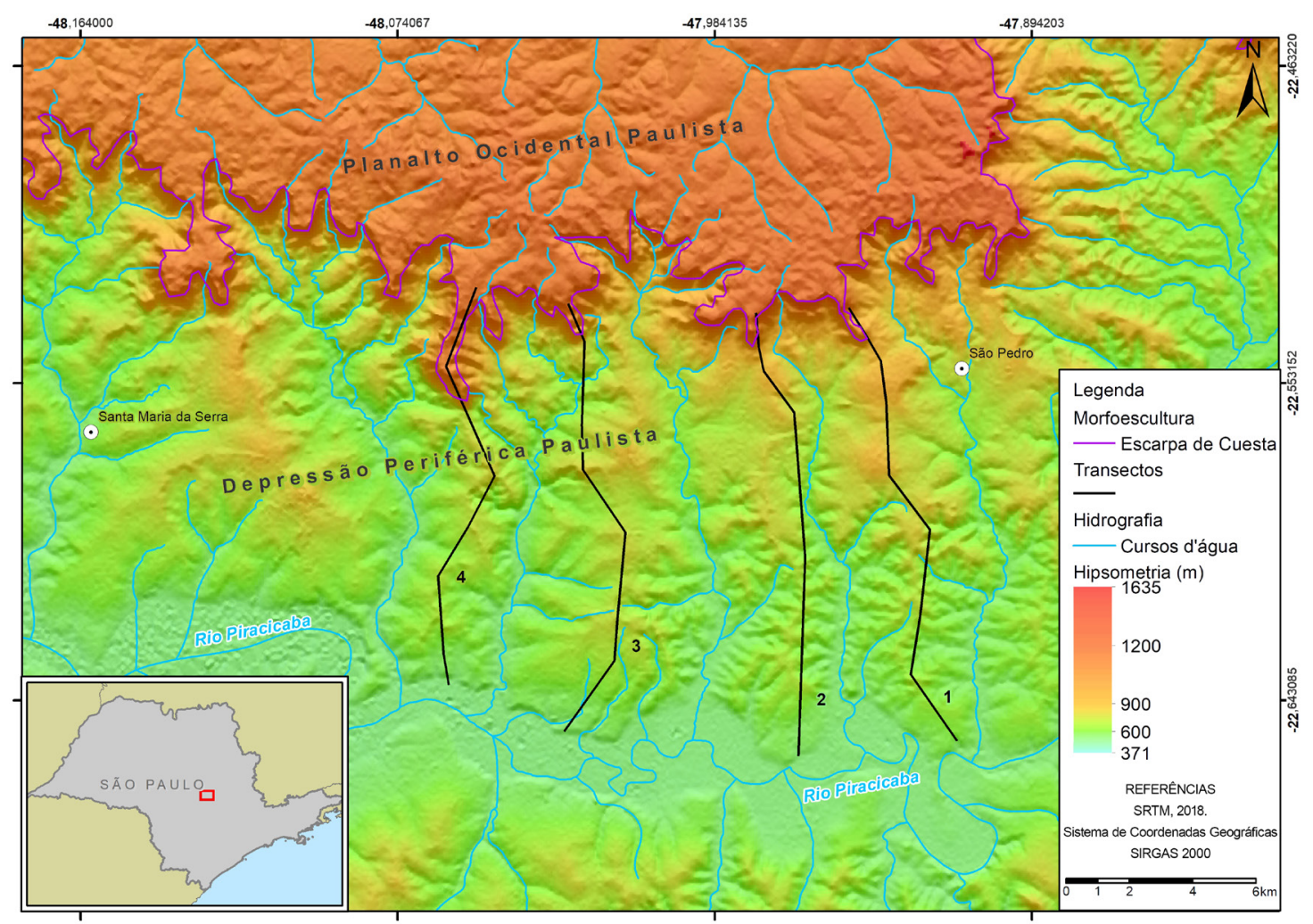

FIGURA 1 - Área de estudo contendo os transectos. 
reverso/front da escarpa até o Rio Piracicaba, na Depressão Periférica.

Após essa análise inicial, utilizou-se o software Global Mapper versão 12 e os dados do Shuttle Radar Topography Mission - SRTM (30 m de resolução espacial) para a confecção dos quatro transectos estudados. No ArcGIS, foram georreferenciadas outras cartas e mapas que serviram de base à confecção dos perfis, sendo estes: mapa síntese de clima do Estado de São Paulo (MONTEIRO 1973), onde verificou-se a classificação climática; mapa geomorfológico do Estado de São Paulo (ROSS \& MOROZ 1997), o qual norteou a compartimentação morfoestrutural e morfoescultural; levantamento pedológico semidetalhado da Folha Piracicaba (OLIVEIRA \& PRADO 1989) e mapa pedológico do Estado de São Paulo (OLIVEIRA et al. 1999) para a classificação dos solos; mapa de vegetação do Brasil (IBGE 1992, IF 2019) para definição das glebas de vegetação; e os mapas geológicos do Estado de São Paulo (ALMEIDA et al. 1981, PERROTTA et al. 2005) para definição da litologia, além das informações sobre o substrato da própria Carta Geomorfológica de São Pedro e do Baixo Piracicaba citada anteriormente.

Utilizando fotografias aéreas (escala 1:25.000) da região (PROSPEC S.A. 1962), foram observadas por estereoscopia mudanças e rupturas de declive e hidrografia, além da cobertura vegetal. A fotointerpretação foi balizada pela análise da Carta Geomorfológica de PINHEIRO \& QUEIROZ NETO (2016), permitindo estabelecer as variações quanto à compartimentação geomorfológica, marcada pela transição do relevo de escarpa de cuesta para o modelado colinoso da Depressão Periférica.

Após essa compilação e associação visual de dados em gabinete, foram feitos trabalhos de campo para a conferência das informações bibliográficas e cartográficas levantadas, além do detalhamento da constituição e estrutura das paisagens com ênfase nos transectos escolhidos. Essa etapa teve como objetivo integrar os dados de escalas diversas, a partir de um levantamento dos elementos naturais e impactos antrópicos em campo, com o objetivo de compatibilizar as informações para a escala de representação dos perfis (1:50.000) seguidos de barras com subdivisões dos fatores da paisagem. Foram analisadas informações sobre tipos de rochas, solos, formas de relevo, cobertura vegetal e uso da terra, que conforme as fontes utilizadas podem apresentar diferenças na caracterização das barras dos perfis geoecológicos.
A organização final e a elaboração de uma síntese dos dados levantados foram feitas a partir da confecção de modelos gráficos sobre a constituição e organização dos elementos naturais e sociais na paisagem, tal como indicado por MONTEIRO (2001). Utilizando-se o software Corel Draw x6 foram elaborados quatro perfis geoecológicos segundo perfis topográficos manualmente confeccionados com base na Carta Geomorfológica de PINHEIRO \& QUEIROZ NETO (2016), demostrando a distribuição vertical e lateral dos elementos ao longo da transição Planalto - Depressão, bem como um perfil síntese, ilustrando as unidades de paisagem diferenciadas pela constituição, organização e dinâmica dos elementos.

Por último, seguindo sugestões da proposta de TROPPMAIR (2000), foram indicados os graus de interações dos elementos, a partir de uma abordagem qualitativa sobre a importância das variáveis para a configuração das unidades de paisagens em escala local. Esta avaliação teve caráter subjetivo, pois foi baseada na análise das referências já citadas sobre a área de estudo, que descreviam as características e interações dos elementos, e na observação direta da paisagem em campo. De modo geral, relações fortes estão presentes entre os elementos com maior destaque na paisagem, como, por exemplo, a interação rocha - relevo na escarpa de cuesta, relações médias nas variáveis secundárias (a exemplo de clima $x$ uso da terra no Planalto Ocidental), relações fracas nos itens que apresentam pouca interação (vegetação $x$ geologia na Depressão Periférica), e relações imperceptíveis entre elementos considerados distintos e com pouca conexão na escala de análise (clima $x$ geologia no planalto e na depressão, por exemplo).

\section{3. Área de estudo}

A área de estudo está localizada nos municípios de São Pedro e Santa Maria da Serra, no Estado de São Paulo, e compreende uma dimensão total de $893,53 \mathrm{~km}^{2}$ (Figura 2). Como mencionado, esta é uma região caracterizada pelo relevo de cuestas que compreende a transição entre o Planalto Ocidental e a Depressão Periférica Paulista (ROSS \& MOROZ 1997). O limite dos perfis geoecológicos inicia-se no limite do Planalto Ocidental, que é o front da escarpa de cuesta, sendo que o sopé dessa última marca o começo da Depressão Periférica.

Conforme PINHEIRO \& QUEIROZ NETO (2015), o Planalto apresenta relevo suave de colinas e morros baixos sustentados por ferricretes e silcretes da Formação Itaqueri, que são 


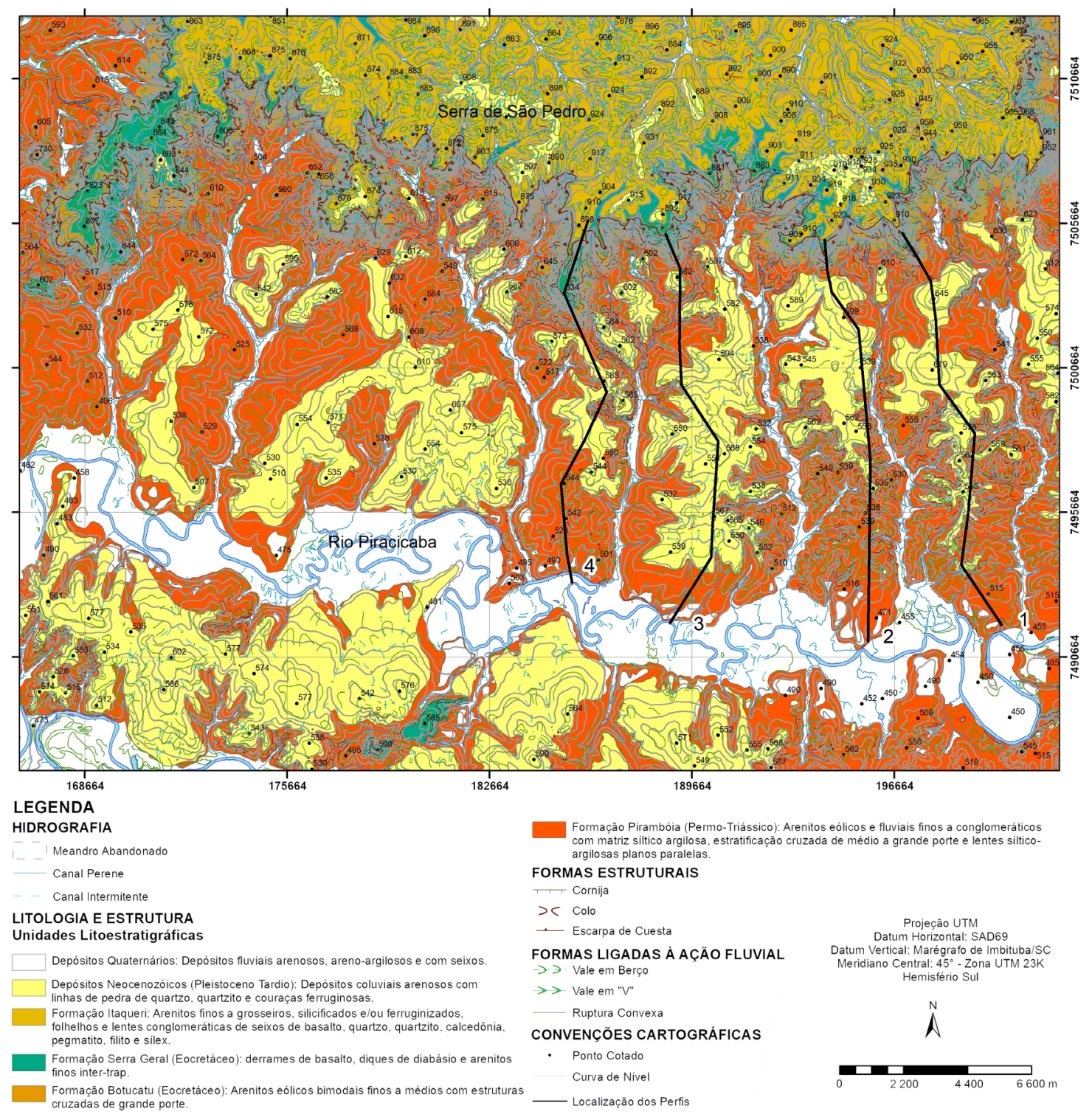

FIGURA 2 - Carta Geomorfológica da Serra de São Pedro e Região do Baixo Piracicaba (PINHEIRO e QUEIROZ NETO 2016) com os transectos dos perfis geoecológicos.

eventualmente capeadas por depósitos arenosos datados do Pleistoceno Superior, entremeados por linhas de pedra. A frente da escarpa apresenta vertentes com declividades bastante elevadas (acima de $30^{\circ}$ ), onde afloram basaltos da Formação Serra Geral e arenitos eólicos da Formação Botucatu, ambos do Eocretáceo. Apesar da orientação geral E-W, a escarpa é festonada, em decorrência do avanço dos canais de drenagem tributários da margem direita do rio Piracicaba (QUEIROZ NETO \& JOURNAUX 1978, PINHEIRO 2014). No sopé da escarpa, na Depressão, formam-se colinas alongadas (glacis ou pedimentos), esculpidas sobre o arenito Pirambóia (Triássico) ou
Depósitos Neocenozóicos (MELO et al. 2001; PINHEIRO \& QUEIROZ NETO 2015, 2016; VILLELA et al. 2018), as quais são dissecadas pelos canais de drenagem que nascem no reverso da Serra (canais principais) e na Depressão (tributários secundários).

$\mathrm{O}$ uso da terra apresenta-se caracterizado por configuração rural (Figura 3), havendo matas ciliares que contornam os tributários do Rio Piracicaba desde o reverso até a planície fluvial na Depressão, recortando diversas glebas geometrizadas que remontam a áreas de cultivo, silvicultura ou pastagem. A maior área urbana consolidada caracteriza a cidade de São Pedro-SP a leste. 


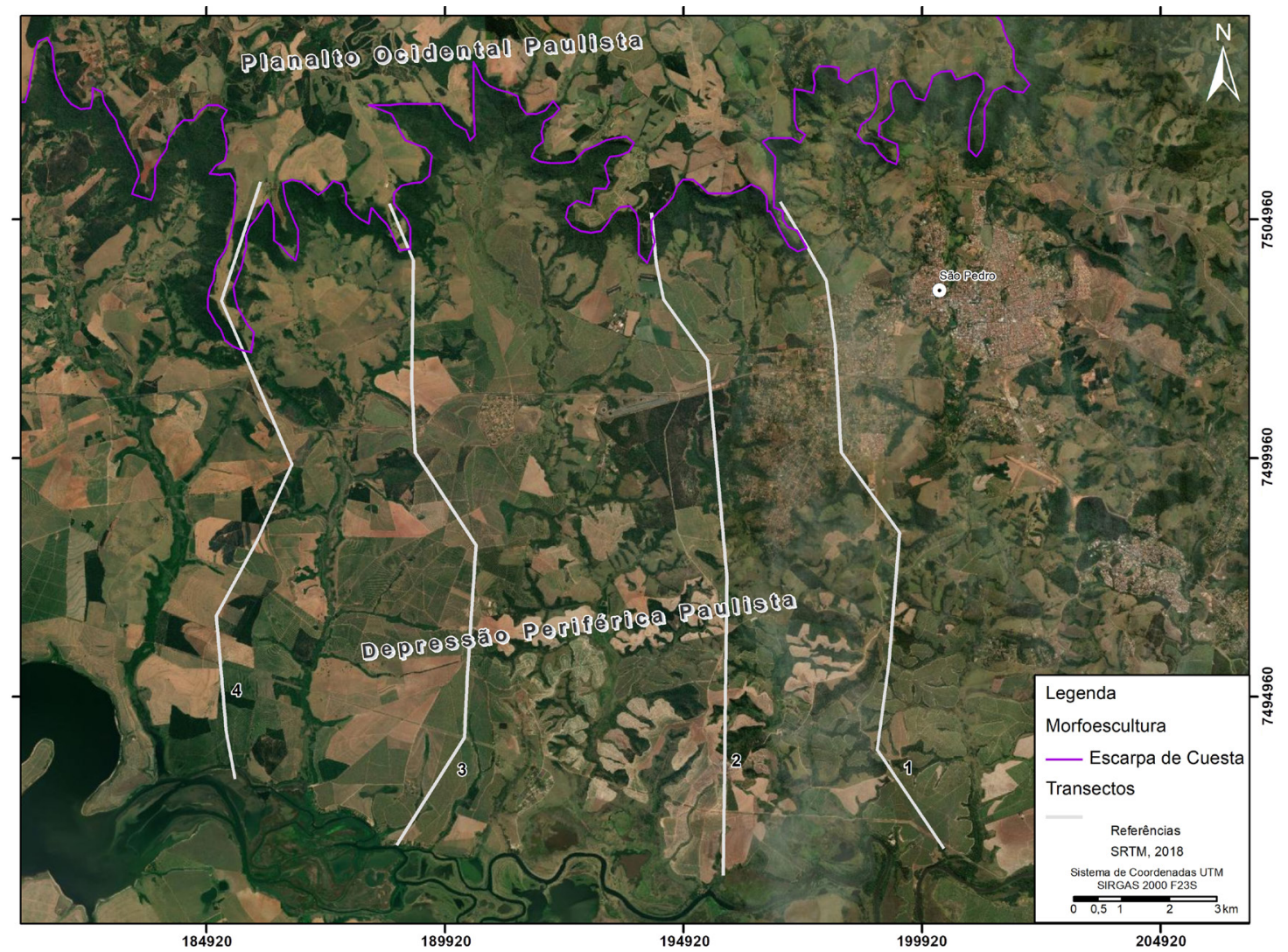

FIGURA 3 - Configuração da área de estudo a partir de imagem do Google Earth (2019) com os transectos dos perfis geoecológicos.

O clima atual é dominado por massas equatoriais e tropicais que configuram estações distintas, uma seca e outra úmida, relacionadas ao "Percée" do Tietê na Depressão Periférica (MONTEIRO 1973). Há possível influência orográfica da cuesta no deslocamento local das massas de ar ou mesmo gradientes de temperatura significativos entre o reverso da escarpa (mais frio e seco) e o sopé da escarpa (mais quente e úmido), mesmo que essas variações não diversifiquem a cobertura original da Floresta Estacional Semidecidual (IBGE 1992, IF 2019).

Todos os perfis iniciam-se no Planalto Ocidental, seguindo pela escarpa de cuesta e avançando até a Depressão Periférica. O Perfil 1 foi traçado entre os divisores topográficos das sub-bacias do Rio Samambaia, que se encontra a Leste, e do Ribeirão do Meio, a Oeste, com uma extensão total de $14.100 \mathrm{~m}$. O Perfil 2 passa pelos divisores das sub-bacias do Ribeirão do Meio, a Leste, e do Rio Vermelho, a Oeste, com extensão total de 13.600 $\mathrm{m}$. O Perfil 3 corresponde ao interflúvio entre as sub-bacias do Ribeirão Vermelho (Leste) e do Ribeirão da Barra (Oeste), com extensão de 13.900 m. Por fim, o Perfil 4 delimita a divisão das sub-bacias do Ribeirão da Barra (Leste) e Rio Tabaranás (Oeste), com extensão de $13.800 \mathrm{~m}$.

\section{RESULTADOS E DISCUSSÕES}

\subsection{Perfil 1 (Figura 4)}

O limite entre o Planalto Ocidental e a Depressão Periférica Paulista ocorre de maneira bem demarcada neste perfil, evidenciando a erosão diferencial ocorrente no reverso, front e sopé da cuesta. A escarpa coincide com o maior gradiente topográfico no perfil, sendo caracterizada pela transição litológica entre a Formação Itaqueri e os basaltos da Formação Serra Geral, o que indica um controle litoestrutural na transição das unidades morfoesculturais do Planalto e Depressão. No compartimento da Depressão ainda há a presença de um morro testemunho, fato que reforça a ideia de um recuo da escarpa por processo remontante e erosão diferencial. 

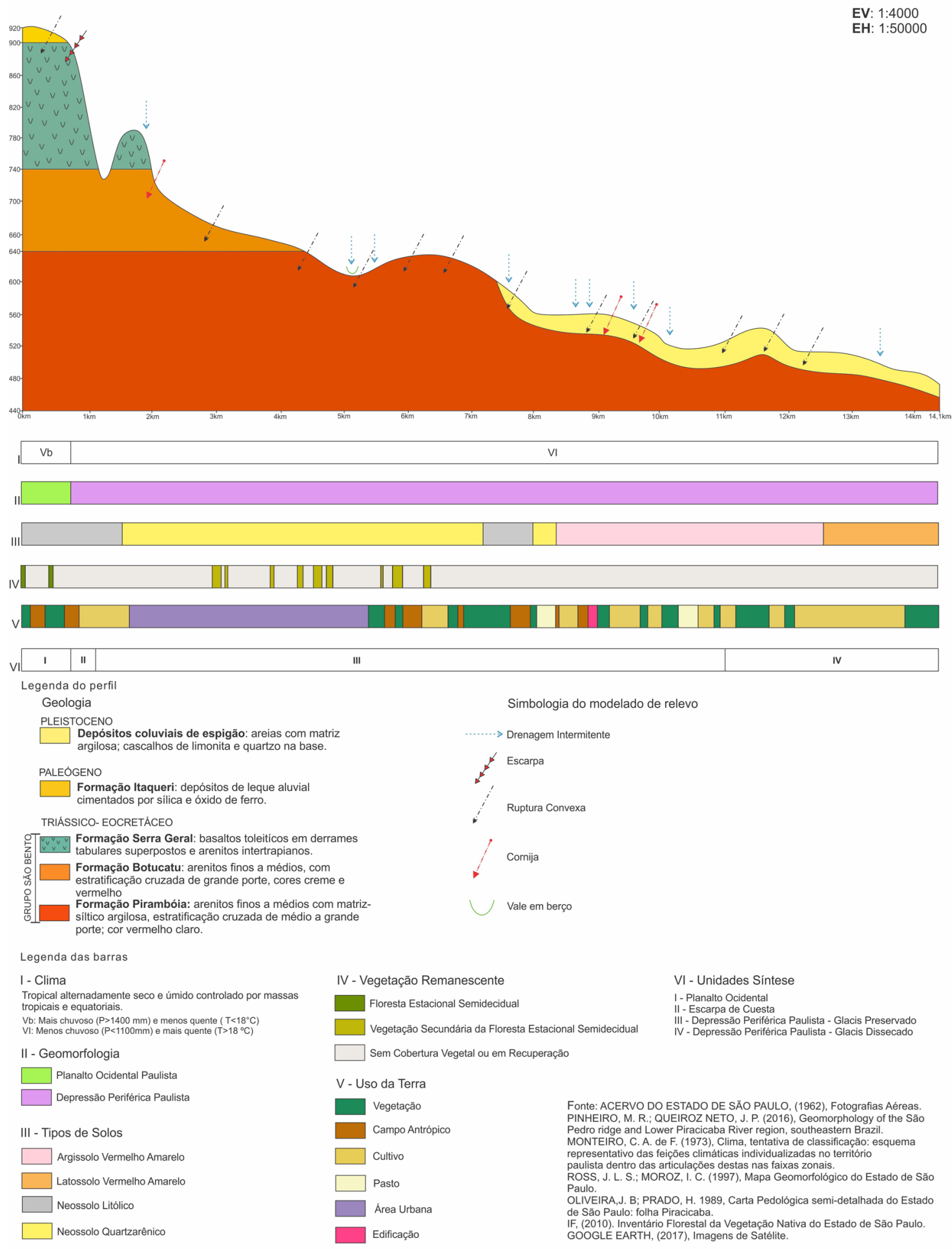

FIGURA 4 - Perfil Geoecológico 1.

Decorrente da configuração litoestrutural e da declividade da escarpa, a cobertura pedológica até o morro testemunho é caracterizada pela ocor- rência de Neossolos Litólicos; em seguida, ao sopé da escarpa, os interflúvios colinosos são dominados pelos Neossolos Quartzarênicos (OLIVEIRA 
\& PRADO 1989). Nesta parte mais conservada do glacis (menor dissecação) vigora no topo das colinas uma cobertura superficial recente (Quaternária), alojada sobre o arenito Piramboia, identificada por PINHEIRO \& QUEIROZ NETO (2016) como "Depósitos Coluviais".

Rumo à jusante para o glacis mais dissecado, a morfologia mais rugosa é acompanhada de rupturas de declive convexas em vertentes sustentadas pela Formação Piramboia, encimada pelos depósitos coluviais na parte superior dos interflúvios. Os solos voltam a adquirir características litólicas ou mantém a classificação quartzarênica, para então ocorrerem predominantemente Argissolos Vermelho ou variações para Latossolos Vermelho-Amarelo, coincidindo com a ocorrência de uma ruptura convexa.

$\mathrm{Na}$ maioria da extensão do Perfil 1 há a predominância de atividades agrárias, porém, quando há transição coincidente entre solo e vegetação, em especial na passagem de Argissolo Vermelho-Amarelo para Latossolo VermelhoAmarelo, o uso da terra caracteriza-se por atividades agrárias entremeadas por remanescentes de vegetação. As categorias de uso da terra permitem inferir que neste transecto há certa homogeneidade do uso, com a ocorrência da classe de área urbana apenas na cidade de São Pedro. Esta, localizada na área do glacis preservado em razão das condições mais favoráveis do relevo quanto à morfologia $\mathrm{e}$ declividade, possui limite ao Norte conforme se aproxima da escarpa até o morro testemunho, e limite ao Sul quando a cidade dá lugar ao uso da terra mais variado, como cultivo (cana de açúcar), silvicultura e pastagem, além da cobertura vegetal secundária.

\subsection{Perfil 2 (Figura 5)}

A transição entre as unidades morfoesculturais do reverso, front e sopé da escarpa de cuesta apresenta-se mais abrupta neste perfil do que no anterior. O limite entre Planalto e Depressão é marcado por drenagem intermitente e aumento significativo da declividade a partir de ruptura convexa, que, seguindo para jusante na altitude de $840 \mathrm{~m}$, marca o início da escarpa sustentada predominantemente pelos basaltos da Formação Serra Geral. $\mathrm{Na}$ cota de $800 \mathrm{~m}$ há ocorrência de uma faceta trapezoidal, indicativa de controle litoestrutural. A passagem da escarpa para a Depressão é marcada por um pequeno colo originado a partir da erosão divergente de duas cabeceiras de drenagem, seguido por um interflúvio convexizado sustenta- do pelas Formações Piramboia e Botucatu. Nesse interflúvio, levantamentos da Topossequência Campestre (VILLELA et al. 2018) indicam uma cobertura pedológica de textura predominantemente arenosa, associada a um material de origem igualmente arenoso e alóctone.

Devido ao controle litoestrutural e à alta declividade da escarpa, em toda sua extensão a cobertura pedológica é composta por Neossolos Litólicos. A passagem do Neossolo Litólico para Neossolo Quartzarênico é marcada, a 2,0 km, por ruptura de declive convexa; esta última classe de solo domina todo o setor do glacis preservado. No glacis dissecado há mudança para Argissolo Vermelho-Amarelo onde as declividades são mais elevadas, predominando até o fim do transecto, mesmo nos trechos em que a declividade é baixa.

É possível observar que os remanescentes secundários da Floresta Semidecidual associados a atividades agrárias são mais presentes do Planalto até a área do glacis preservado, o que indica que a maior declividade da escarpa permitiu a conservação destes fragmentos.

O uso da terra é variado. Do Planalto Ocidental até o glacis preservado, além da maior ocorrência de vegetação secundária, ocorre também cultivo de cana de açúcar, bem como glebas de silvicultura. No glacis dissecado até o final da extensão do Perfil 2, configura-se a maior variabilidade no uso da terra, com predomínio do cultivo de cana e ocorrência de vegetação secundária, silvicultura e áreas de pastagem.

\subsection{Perfil 3 (Figura 6)}

A morfoescultura no Perfil 3 segue o mesmo padrão do Perfil 2, com transição abrupta do Planalto para a Depressão. A escarpa de cuesta é sustentada por basaltos da Formação Serra Geral, e, na transição desta para a Formação Botucatu, pode-se observar a diferença na morfologia do modelado, resultado do processo remontante e da erosão diferencial responsáveis pelo recuo da escarpa. Ainda, é possível notar maior dissecação na Formação Piramboia, ficando evidente o controle litoestrutural na configuração do modelado. Por fim, há a ocorrência de um pequeno colo separando o primeiro interflúvio da Depressão Periférica do front da escarpa, tal qual o Perfil 2, embora a declividade seja mais acentuada na direção jusante.

No topo da escarpa, encimando o modelado do Planalto Ocidental, Neossolos Litólicos predominam até o sopé da escarpa. A transição dos so- 


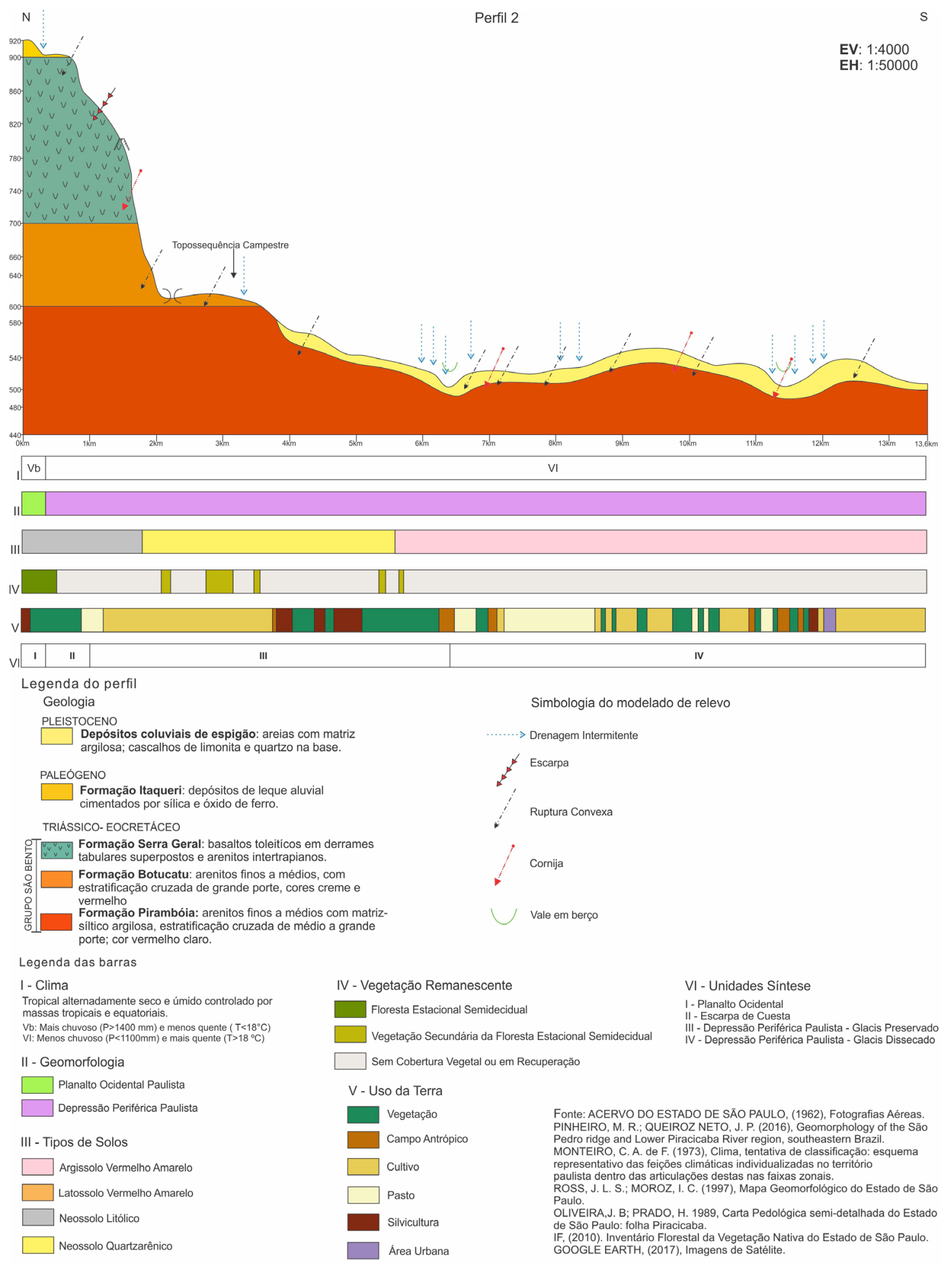

FIGURA 5 - Perfil Geoecológico 2.

los litólicos para o Argissolo Vermelho-Amarelo é marcada pelo colo mencionado acima, seguido pelos Neossolos Quartzarênicos e Latossolos Vermelho-Amarelos. O modelado de relevo é marcado por drenagens intermitentes e vales em berço associados a colinas com menor declividade, característica essa mais propícia ao desenvolvimento dos Latossolos. 


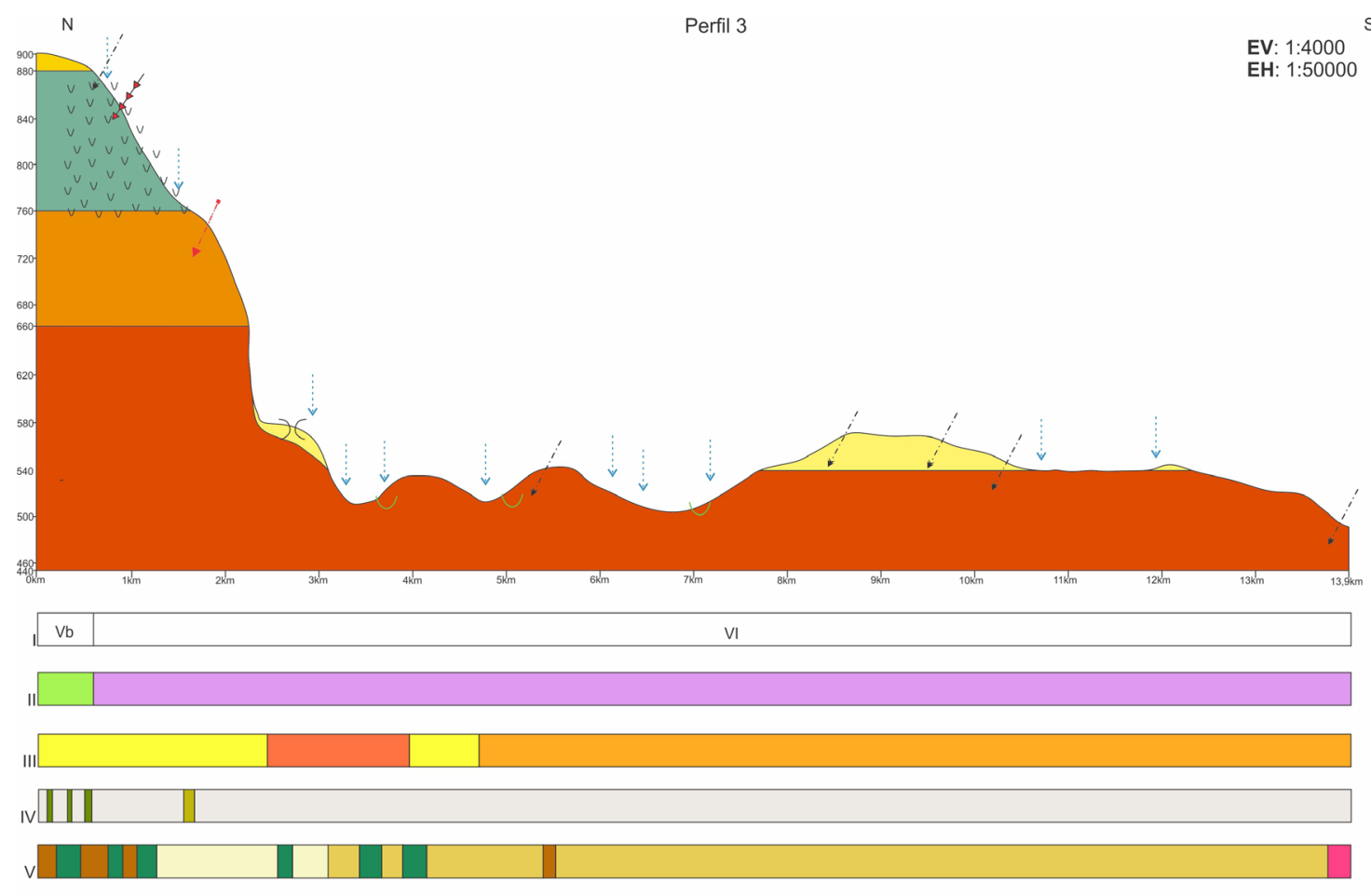

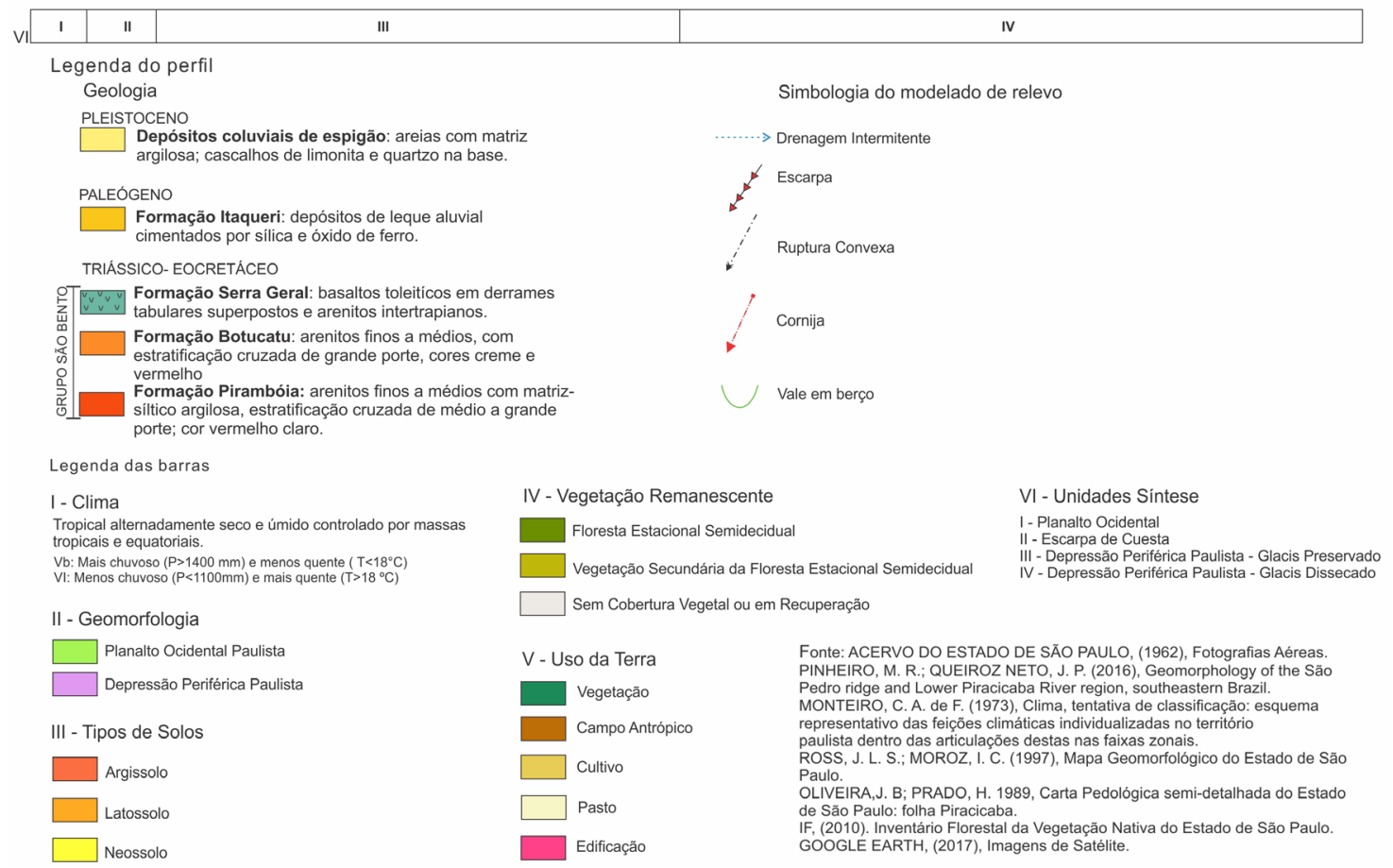

FIGURA 6 - Perfil Geoecológico 3.

Remanescentes preservados da Floresta Estacional Semidecidual ocorrem nos setores escarpados da cuesta. Do topo do Planalto até a escarpa de cuesta o uso da terra é variável, com vegetação e campo antrópico, provavelmente devido à alta declividade do terreno que dificulta a ocupação humana. Da escarpa até a transição dos Argissolos para Neossolos (em sua maioria Quartzarênicos, mas podendo ocorrer eventualmente Litólicos), o uso da terra ainda é variável, contudo, há predomínio de áreas de pastagem. Até o final da extensão do perfil, o terreno é quase que totalmente utilizado para cultivo. 


\subsection{Perfil 4 (Figura 7)}

O Perfil 4 assemelha-se aos Perfis 2 e 3, com transição abrupta do Planalto para a Depressão em função da litoestrutura. O setor do reverso é o mais extenso dos perfis e caracteriza-se pela presença de rupturas, mudanças de declive e vales em berço.
Nesse caso, o menor recuo da escarpa indica uma maior resistência à erosão.

O Perfil 4 inicia-se com a predominância de Latossolos no Planalto Ocidental; em seguida, na escarpa, passa para Neossolos Litólicos. A transição de solos rasos para o Latossolo é marcada pela ocorrência de cornija. Já na área do glacis preser-

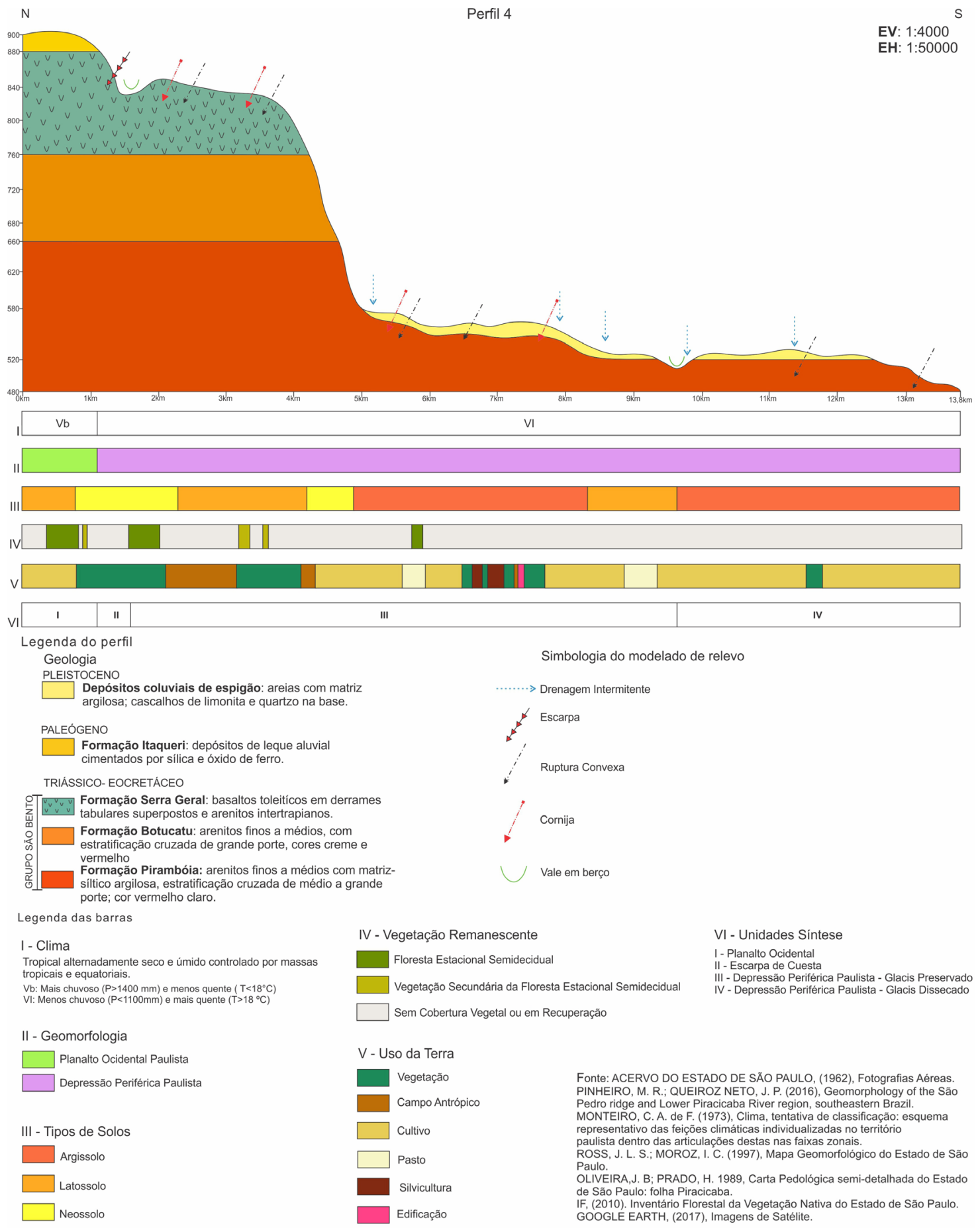

FIGURA 7 - Perfil Geoecológico 4. 
vado, o solo é composto por Argissolo VermelhoAmarelo, com transição para Latossolo VermelhoAmarelo, marcada também pela ocorrência de cornija. Esta classe de solo domina o perfil até um vale em berço, que marca a transição para Argissolo novamente, que compõe o restante do perfil.

Assim como no Perfil 3, é possível relacionar a vegetação com a compartimentação geomorfológica e o uso da terra. Os fragmentos vegetacionais ocorrem de maneira mais concentrada em áreas com maior declividade (escarpa), ou em fragmentos vegetacionais de nichos de nascente nas colinas do glacis preservado; no domínio da Depressão Periférica, cujas áreas com menor declividade facilitam a ocupação humana, o uso é marcado pela predominância da agricultura.

A todos os perfis geoecológicos valem as subdivisões indicadas por MONTEIRO (1973) quanto à dinâmica climática alternadamente seca e úmida controlada por massas tropicais e equatoriais: no Planalto Ocidental predomina o tipo climático $\mathrm{Vb}$, mais chuvoso ( $\mathrm{P}>1.400 \mathrm{~mm}$ ) e menos quente $\left(\mathrm{T}<18^{\circ} \mathrm{C}\right)$, e na Depressão Periférica predomina o clima de tipo VI, menos chuvoso $(\mathrm{P}<1.100$ $\mathrm{mm})$ e mais quente $\left(\mathrm{T}>18^{\circ} \mathrm{C}\right)$. No entanto, deve-se ressaltar que estas variações nem sempre acompanham as compartimentações geomorfológicas, dado o caráter dinâmico das massas de ar.

\subsection{Síntese}

A partir da integração dos resultados e de uma análise qualitativa dos transectos, foi elaborado um Perfil Síntese, que representa a distribuição horizontal das unidades de paisagem e os níveis de interações dos elementos que as compõem (Figura 8). Foram identificadas quatro unidades, que correspondem a arranjos homogêneos do ponto de vista da constituição, organização e funcionamento dos elementos: I) Planalto Ocidental, II) Escarpa de Cuesta, III) Depressão Periférica - Glacis Preservado, IV) Depressão Periférica- Glacis Dissecado. Esta divisão coincide com a proposta de compartimentação geomorfológica indicada por PINHEIRO \& QUEIROZ NETO (2016), devido, em grande parte, à escala de abordagem e às influências morfoestruturais e morfoesculturais locais.

A unidade I, correspondente ao compartimento morfoescultural do Planalto Ocidental Paulista (reverso da escarpa de cuesta), aponta interações fortes entre os elementos relacionados ao clima, remanescentes de vegetação e solos, além de uma interação direta entre a geomorfologia, solos e uso da terra. Tais associações são compreen- síveis, pois esta unidade de paisagem encontra-se individualizada das demais como o setor de maior altitude e com influência orográfica das massas de ar dos sistemas frontais, havendo menor variação nas transições geoecológicas horizontais e ocupação intercalada entre fragmentos de vegetação secundária (muitas vezes circundando as cabeceiras de drenagem) e campos antrópicos, assim como áreas de cultivo de cana de açúcar ou silvicultura. Os solos, caracterizados por Neossolos Litólicos decorrentes da alteração do substrato arenítico-basáltico, podem também dar lugar a Neossolos Quartzarênicos e Latossolos Vermelho-Amarelos.

A unidade II corresponde à escarpa de cuesta propriamente dita, com altas declividades e forte controle litoestrutural: o edifício arenítico-basáltico sustenta o relevo da escarpa, que em razão de seu gradiente acentuado inibe o desenvolvimento dos solos e a ocupação antrópica; em função do clima alternadamente seco e úmido ocorrem fragmentos da vegetação original de Floresta Estacional Semidecidual ou vegetação secundária.

As unidades de paisagem III e IV são muito similares em relação às interações entre os elementos, pois ambas caracterizam o compartimento da Depressão Periférica Paulista, divididas respectivamente em Glacis Preservado, cujo modelado de relevo possui menor entalhamento, com interflúvios mais amplos, e Dissecado, cujo entalhamento é mais expressivo. Em ambas as unidades as interações são fortes entre os elementos relacionados à geomorfologia, solos e uso da terra, pois há as melhores condições topográficas e de desenvolvimento de solos para a ocupação antrópica e cultivo agrícola, além de haver clima mais seco se comparado à Unidade I. Porém, pode ser destacada uma diferença entre estas duas unidades de paisagem quanto à interação entre o uso da terra $\mathrm{e}$ a geomorfologia: enquanto na unidade III (Glacis Preservado) esses elementos são fortemente associados, na unidade IV (Glacis Dissecado) esta interação é média, o que pode ser explicado pelas condições mais aplainadas da superfície na primeira, fato que inclusive justifica a localização do sítio urbano da cidade de São Pedro.

No Quadro 1 é apresentada a articulação geral dos elementos, com o objetivo de sintetizar as discussões anteriores. Esse quadro mostra as unidades de paisagem, seus elementos, características e principais interações, complementando as ideias expostas na figura 8. 

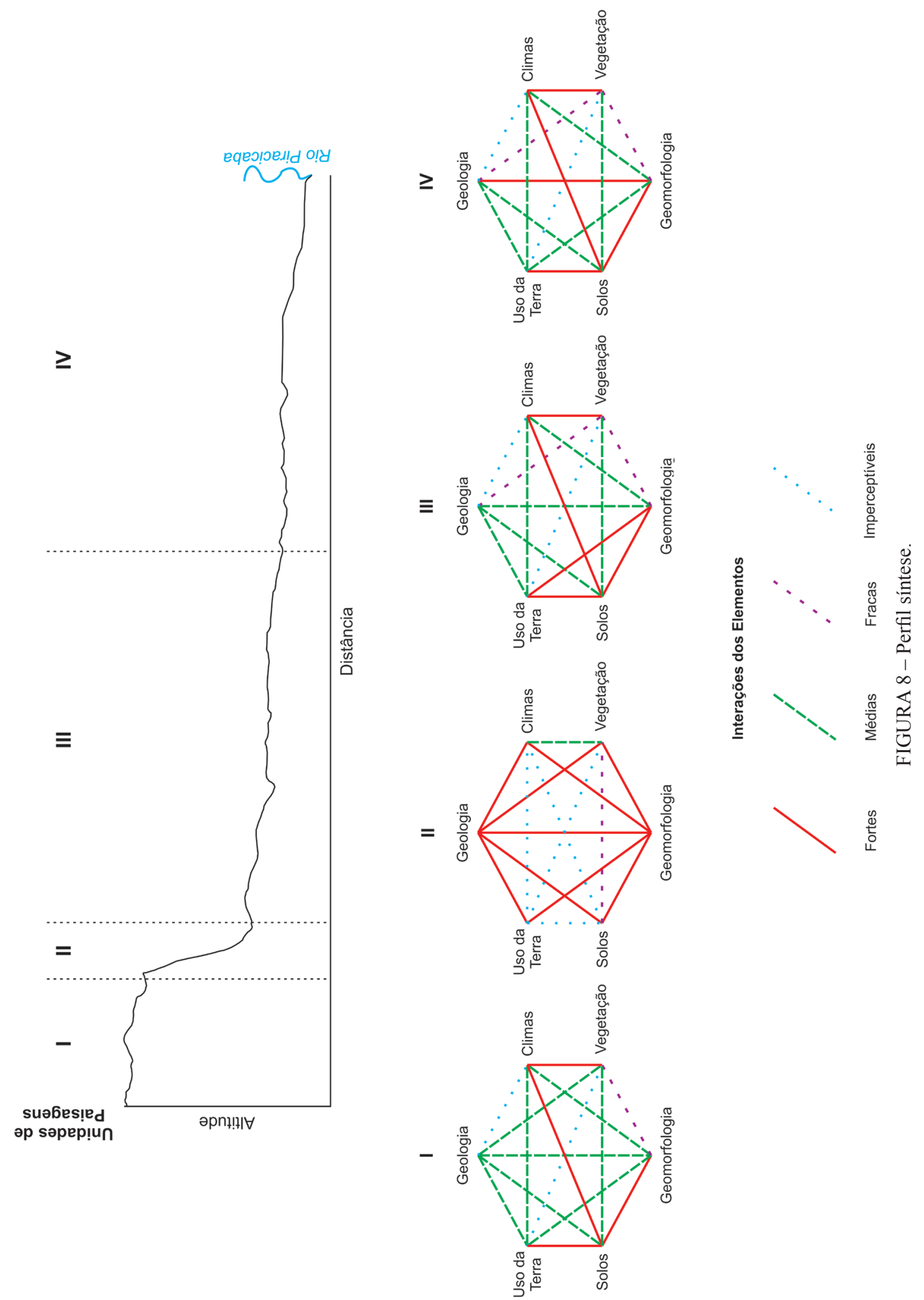


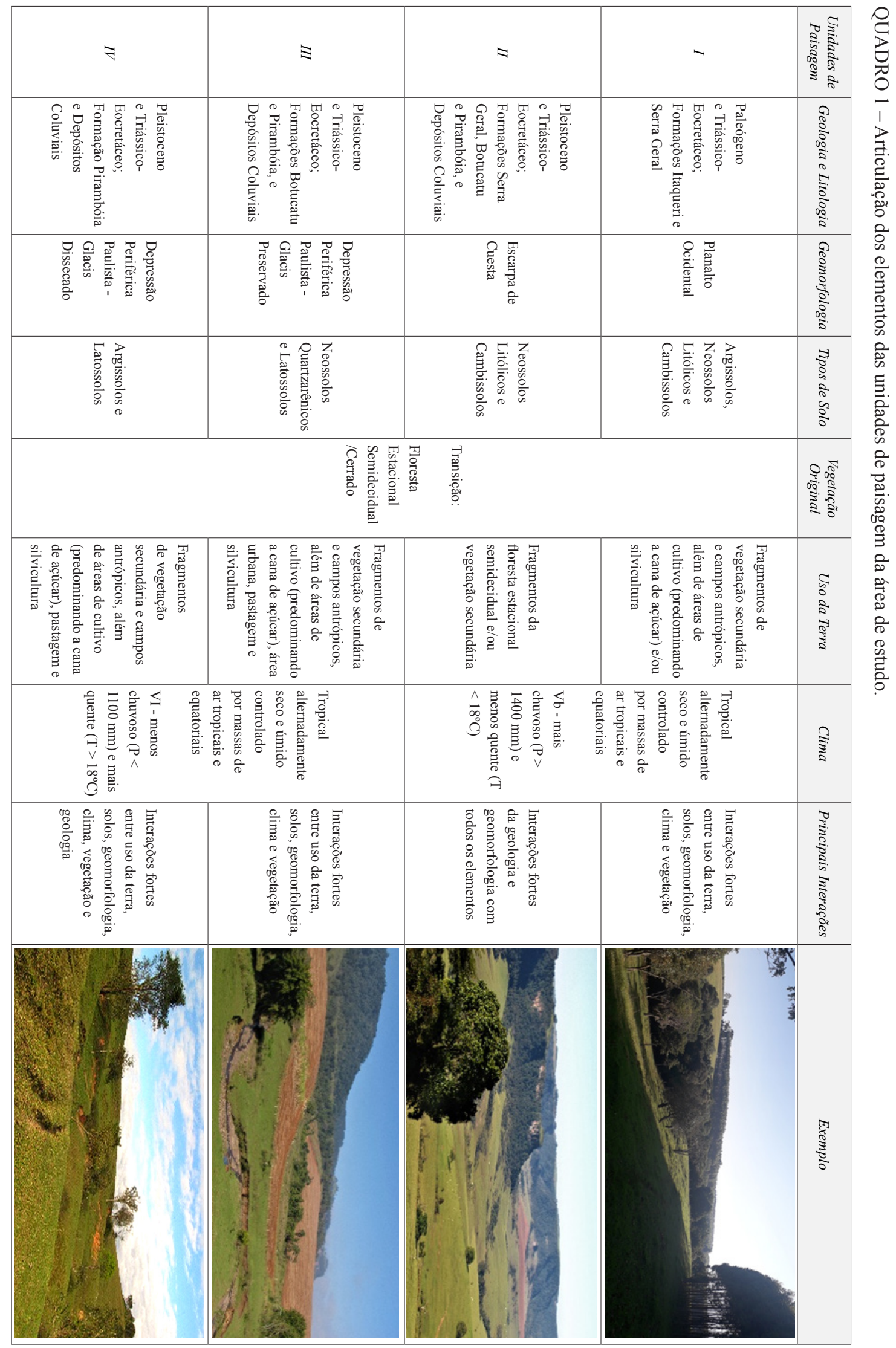




\section{CONSIDERAÇÕES FINAIS}

De modo geral, a caracterização dos perfis geoecológicos permite inferir que os elementos naturais e antrópicos estão sendo influenciados pela compartimentação geomorfológica (morfoescultural), que por sua vez sofre toda influência das características litoestruturais na transição Planalto Ocidental - Depressão Periférica.

Os resultados permitiram relacionar elementos envolvidos na dinâmica de uma paisagem de modo a proporcionar uma hierarquização. $\mathrm{Na}$ área de estudo, esta não foi definida segundo a percepção do pesquisador, mas sim de acordo com a dimensão do fenômeno, sendo possível perceber a forte relação entre os elementos do sistema.

A partir da construção de perfis geoecológicos foi possível descrever a constituição e organização da estrutura superficial das paisagens na transição Planalto - Depressão, bem como fazer algumas inferências sobre a interação entre os elementos. Registrou-se ainda a diferença de denudação nos compartimentos geomorfológicos. No Planalto Ocidental, o relevo apresenta-se mais preservado, com baixo índice de dissecação. Já na Depressão Periférica, a denudação e agradação atuaram e atuam de forma intensa, ocasionando o recuo da escarpa de cuesta por processo erosivo remontante principalmente nas colinas sustentadas por substratos sedimentares.

A metodologia dos perfis geoecológicos permite uma compreensão parcial e preliminar da estrutura e dinâmica das paisagens, isto é, a hierarquização espacial e temporal dos elementos segundo seus níveis de atuação e como estes influenciam na caracterização das paisagens atuais. O controle litoestrutural é o elemento com maior influência na área, pois direciona a organização do restante da paisagem, desde a formação de solos à ocupação antrópica.

\section{AGRADECIMENTOS}

Os autores agradecem ao CNPq, pela bolsa PIBIC de iniciação científica, à FAPESP pelos fomentos concedidos nos Processos 2016/08722-3 e 2017/14791-0, e à CAPES pela bolsa PNPD, além da contribuição da revisão de pares.

\section{REFERÊNCIAS BIBLIOGRÁFICAS}

AB'SÁBER, A.N. 1969. Um conceito de Geomorfologia a serviço das pesquisas sobre o Quaternário. Geomorfologia, 18: 23 p.

AB'SÁBER, A.N. 1972. Participação das Depressões Periféricas e Superfícies Aplainadas na Compartimentação do Planalto Brasileiro. Geomorfologia, 28: 1-38.

ALMEIDA, F.F.M. 1949. Relevo de Cuesta na Bacia Sedimentar do Rio Paraná. Boletim Paulista de Geografia 3: 21-33.

ALMEIDA, F.F.M.; HASUI, Y.; PONÇANO, W.L.; DANTAS, A.S.L.; CARNEIRO, C.D.R.; MELO, M.S.; BISTRICHI, C.A. 1981. Mapa Geológico do Estado de São Paulo - Escala 1:500.000. São Paulo, Instituto de Pesquisas Tecnológicas, 2 vols.

BEROUTCHACHVILI, N.; RADVANYI, J. 1978. Les structures verticales des géosystèmes. Revue géographique des Pyrénées et du SudOuest, t. 49(2): 181-198.

BERTALANFFY, L.V. 1950. An outline of General System Theory. The British Journal for the Philosophy of Science 1(2): 134-165. https:// doi.org/10.1093/bjps/I.2.134

CIANFARRA, P.; PINHEIRO, M.R.; SALVINI, F.; VILLELA, F.N.J. 2018. Neotectonic of São Pedro region (São Paulo, Brazil) revealed by recent fault and fracture inversion by Montecarlo approach. In: EGU, EGU GENERAL ASSEMBLY 2018, Viena, Geophysical Research Abstracts, 20: EGU2018-17010-2.

CONTI, J.B. 2011. Resgatando a "Fisiologia da Paisagem". Revista do Departamento de Geografia, 14: 59-68. https://doi. org/10.7154/RDG.2001.0014.0006

DELPOUX, M. 1974. Ecossistema e paisagem. São Paulo: Instituto de Geografia - USP, 23 p. (Métodos em questão, 7).

DIAS FERREIRA, R.P. 1997. Solos e Morfogênese em São Pedro. Departamento de Geografia, Faculdade de Filosofia, Letras e Ciências Humanas, Universidade de São Paulo, São Paulo, Tese de Doutorado, 157 p. 
FURQUIM, S.A.C. 2002. Interações entre modelado e solo no transecto Espraiado, São Pedro, SP. Departamento de Geografia, Faculdade de Filosofia, Letras e Ciências Humanas, Universidade de São Paulo, São Paulo, Dissertação de Mestrado, 146 p. https://doi.org/10.11606/D.8.2002.tde01082005-105035

FURQUIM， S.A.C.; COLTRINARI，L.; DIAS FERREIRA, R.P.; CASTRO, S.S.; PUGLIESE, G.R. 2013. Lamellae Formation Processes in Tropical Soils in Southeastern Brazil. Catena, 107: 15-25. https://doi. org/10.1016/j.catena.2013.03.005

GOUDIE, A. 2014. Alphabetical Glossary of Geomorphology. International Association of Geomorphologists. Disponível em http://www.geomorph.org/wp-content/ uploads/2015/06/GLOSSARY_OF_ GEOMORPHOLOGY1.pdf Acessado em out. 2019.

IBGE - Instituto Brasileiro de Geografia e Estatistica. 1992. Mapa de Vegetação Atual. In: Atlas Nacional do Brasil, IBGE, Rio de Janeiro.

IF - INSTITUTO FLORESTAL DO ESTADO DE SÃO PAULO. 2019. Inventário Florestal da Vegetação Nativa do Estado de São Paulo. Disponível em https://smastr16.blob.core. windows.net/sifesp/2013/12/mapainventario. pdf. Acessado em 14 dez. 2019.

MANOSSO, F.C. 2008. Estudo integrado da paisagem nas regiões norte, oeste e centrosul do Estado do Paraná: relações entre a estrutura geoecológica e a organização do espaço. Boletim de Geografia, 26/27(1): 81-94. https://doi.org/10.4025/bolgeogr. v0i0.7934

MANOSSO, F.C. 2013. Integração vertical e horizontal da paisagem, uma aplicação da teoria da paisagem. Ensaios de Geografia, 2(4): $67-86$

MELO, M.S., COIMBRA, A.M., CUCHIERATO, G. 2001. Genesis of Quaternary colluvial eluvial sedimentary covers in southeastern Brazil. Quaternaire, 12(3): 179-188. http:// dx.doi.org/10.3406/quate.2001.1691
MONTEIRO, C.A.F. 1973. A dinâmica climática e as chuvas no estado de São Paulo: estudo geográfico sob forma de atlas. Instituto de Geografia, São Paulo, 130 p.

MONTEIRO, C.A.F. 2001. Geossistemas: a história de uma procura. Ed. Contexto, São Paulo, $2^{\mathrm{a}}$ ed., $127 \mathrm{p}$.

OLIVEIRA, D. 1997. Estudo Macro e Micromorfológico de uma Topossequência na Bacia do Córrego do Retiro de São Pedro-SP. Faculdade de Filosofia, Letras e Ciências Humanas, Universidade de São Paulo, São Paulo, Dissertação de Mestrado, 143 f. https://doi.org/10.11606/D.8.1997.tde23092003-152122

OLIVEIRA, J.B; PRADO, H. 1989. Carta pedológica semi-detalhada do Estado de São Paulo: Folha Piracicaba. São Paulo, IAC - Instituto Agronômico / IGC - Instituto Geográfico e Cartográfico. Escala 1:100 000.

OLIVEIRA, J.B.; CAMARGO, M.N.; ROSSI, M.; CALDERANO FILHO, B. 1999. Mapa Pedológico do Estado de São Paulo - escala 1:500.000. IAC/EMBRAPA, Campinas.

PERROTTA, M.M.; SALVADOR, E.D.; LOPES, R.C.; D'AGOSTINO, L.Z.; PERUFFO, N.; GOMES, S.D.; SACHS, L.L.B.; MEIRA, V.T.; GARCIA, M.G.M.; LACERDA FILHO, J.V. 2005. Mapa Geológico do Estado de São Paulo, escala 1:750.000. Programa Geologia do Brasil - PGB, CPRM, São Paulo.

PINHEIRO, M.R. 2014. Estudo morfotectônico da região da Serra de São Pedro e do Baixo Piracicaba/SP. Departamento de Geografia, Faculdade de Filosofia, Letras e Ciências Humanas, Universidade de São Paulo, São Paulo, Tese de Doutorado, 286 p. https://doi.org/10.11606/T.8.2014.tde11052015-170604

PINHEIRO, M.R.; QUEIROZ NETO, J.P. 2015. Neotectônica e evolução do relevo da região da Serra de São Pedro e do baixo Piracicaba/ Sudeste do Brasil. Revista Brasileira de Geomorfologia, 16: 593-613. http://dx.doi. org/10.20502/rbg.v16i4.668

PINHEIRO, M.R.; QUEIROZ NETO, J.P. 2016. Geomorphology of the São Pedro ridge and 
Lower Piracicaba River region, southeastern Brazil. Journal of Maps, 12(1): 377-386. https://doi.org/10.1080/17445647.2016.122 7730

PINHEIRO, M.R.; QUEIROZ NETO, J.P. 2017. From the semiarid landscapes of southwestern USA to the wet tropical zone of southeastern Brazil: Reflections on the development of cuestas, pediments, and talus. Earth-Science Reviews, 172: 27-42. https:// doi.org/10.1016/j.earscirev.2017.07.005

PINHEIRO, M.R.; CIANFARRA, P.; VILLELA, F.N.J.; SALVINI, F. 2019. Tectonics of the Northeastern border of the Parana Basin (Southeastern Brazil) revealed by lineament domain analysis. Journal of South American Earth Sciences, 94: 102231. https://doi. org/10.1016/j.jsames.2019.102231

PROSPEC S.A. 1962. Levantamento Aerofotogramétrico do Estado de São Paulo. Escala 1:25.000.

QUEIROZ NETO, J.P.; JOURNAUX, A. 1978. Carta geomorfológica de São Pedro, SP, Escala 1:50.000. Convênio Laboratório de Sedimentologia e Pedologia do Departamento de Geografia/FFLCH/USP / Centre de Géomorphologie du CNRS - CAEN.
ROCHA, A.S.; NÓBREGA, M.T.; CUNHA, J.E. 2018. As unidades de paisagem, as vertentes características e os sistemas pedológicos na bacia hidrográfica do Paraná 3. Ateliê Geográfico, 12(1): 51-70.

ROSS, J.L.S.; MOROZ, I.C. 1997. Mapa Geomorfológico do Estado de São Paulo. Escala 1:500.000. São Paulo, 2 vols.

TROLL, C. 1971. Landscape Ecology (Geoecology) and Biogeocenology - a terminological study. Geoforum, 2(4): 43-46. https://doi. org/10.1016/0016-7185(71)90029-7

TROPPMAIR, H. 2000. Geossistemas e geossistemas paulistas. UNESP, Rio Claro, $107 \mathrm{p}$.

VILLELA, F.N.J.; PINHEIRO, M.R.; QUEIROZ NETO, J.P.; MANFREDINI, S.; ALVES, G.B.; BARREIROS, A.M.; NAKASHIMA, M.R.; SCIGLIANO, B. F.; MICHELON, C.R.; SANTOS, A.A.; SOARES, A.F.A.; BORSOI, H.R.G.; MELO, G.V.; SANTOS, R.F. 2018. Evolução do Modelado de Relevo e dos Materiais no Sopé da Escarpa de Cuesta de São Pedro-SP. Revista de Geografia (Recife), 35(4): 131-144.

\section{Endereço dos autores:}

Fernanda Ramos, André Mateus Barreiros, Fernando Nadal Junqueira Villela e Marcos Roberto Pinheiro - Departamento de Geografia, Faculdade de Filosofia, Letras e Ciências Humanas, Universidade de São Paulo, Avenida Lineu Prestes, 338, CEP 05508-080, Cidade Universitária, São Paulo, SP. E-mails: fernanda.ramos@usp.br; andrembarreiros@gmail.com; geovillela@usp.br; m3279574@usp.br

Artigo submetido em 13 de novembro de 2019, aceito em 30 de dezembro de 2019. 